\title{
Identifying Techniques for Encouraging Compassionate Communication: Supporting Behaviour for International Primary School Students in Shanghai, China
}

\author{
Melissa D. Arnesen-Trunzo \\ University of Sunderland, Sunderland, UK \\ Email: melissaarnesentrunzo@yahoo.com, productionsma@gmail.com
}

Received February 2015

\begin{abstract}
Techniques for encouraging compassionate communication were created by Melissa ArnesenTrunzo in 2012 in response to providing younger learners with the skills needed to communicate and support positive behavior in the classroom. The techniques developed support young learners with where they are cognitively and respect cultural and language differences found in international classrooms. Combining ideas developed for Nonviolent Communication by Marshall Rosenberg and using David Kolb's Experiential Learning Theory, techniques were designed to support young learners with their cognitive and social needs. The techniques used allow young learners to develop awareness of their actions and words when conflicts arise in the classroom. Cards, roleplays, drawings, discussions, and reflections are some of the techniques that were used when a conflict occurred. The techniques are still being explored, but can be adapted for whole groups, small groups, and individual learners. These techniques have been used to bolster positive behavior in the classroom, active communication among peers, and limit teacher involvement; allowing learners to take an active role in communicating their feelings and needs.
\end{abstract}

\section{Keywords}

Communication, Techniques, Language, Young Learners, Behavior

\section{Aim of the Study}

The aim of this study is to explore the effectiveness and use of Compassionate Communication Techniques, based on ideas presented in the process of Nonviolent Communication or NVC (Rosenberg and Rosenberg, 2003) [1], in an English as a Second Language (ESL) and Chinese Grade One boarding school's classroom.

\section{Rationale}

Compassionate Communication Techniques were developed in response to a behaviour policy in the re- 
searcher's school, stating that no disciplinary actions or forms of punishment may take place (Teachers Regulations, 2014) [2]. The techniques used to encourage Compassionate Communication echo ideas and steps designed by Dr. Marshall B. Rosenberg in his book Nonviolent Communication (2003) [1]. However, they should not be considered Nonviolent Communication, as they do not follow his recommended procedure and the teachers guiding the process are not NVC trained. Cultural and curricular aims were considered when designing these Compassionate Communication strategies. It should also be noted that Dr. Rosenberg's (2003) practice, the essence of Nonviolent Communication (NVC) does not encourage acts of apology, as these are associated with negative energy (shame and judgement) and have no real connection to the putative healing process brought about through the identification of what is needed by the parties involved (Rosenberg and Rosenberg, 2003, pp. 130-134) [1]. However, "apologies" were allowed in order to support language that would be seen in English-related dialogue and used for assessments in this context. Therefore, this form of behaviour encouragement should not be seen as Nonviolent Communication.

Over the course of this study, images, cards, individual and group reflections and immediate responses to conflicts, were used to support understanding and use of Compassionate Communication for a grade one class. This echoes ideas found in David Kolb’s Experimental Learning Theory (Beard, Wilson and Beard, 2006) [3]. Effectiveness and use of techniques were explored using a variety of methods including: interviews with both students and teachers, systematic and participant observations done both in and outside the classroom, and documents created by the students, and from observations for data collection (Denscombe, 2010) [4]. By examining both the learning objectives and evaluating the effectiveness and use of Compassionate Communication Techniques in the classroom a deeper awareness of the positive and negative effects of the techniques were developed and alterations were made and continue to be made (Wellington, 2000, pp. 133-134) [5].

Behaviour management in the researcher's grade one (ages 6 - 7) classroom was challenging due to the boarding school context and the behaviour policy, that no disciplinary actions or forms of punishment were allowed to be dispensed on school campus (Teachers Regulations, 2014) [2]. No explicit support on how teachers might encourage positive behaviour has been shared with the practitioners in this Primary Years Program (PYP) division since the writing of this paper.

The researcher has explored many strategies developed by single-subject teachers to support positive behaviour in the classroom, including a star system and awards for good behaviour. The development of generating skills associated with supporting personal behaviour strategies were limited to teachers authorizing awards though this did not prevent conflicts among students from arising. A plan that used Compassionate Communication and supported both ESL and its attendant development of communication skills, were created after reviewing lecture notes on a Nonviolent Communication course (Liedl, 2012) [6]. This was further enhanced by this researchers reading of bookson Marshall Rosenberg's Nonviolent Communication (Rosenberg and Rosenberg, 2003) [1] process and David Kolb’s Experimental Learning Theory (Kolb, 1984) [7].

\section{Background to the Context of This Study}

This researcher had an opportunity to take a Compassionate Communication course in January of 2012 at El INVU de Peñas Blancas, Alajuela, Costa Rica. During this course Sue Liedl, founder and trainer at Peacemaker Resources Incorporated, held lectures. Notes and ideas surrounding Compassionate Communication in order to identify areas of conflict and areas of peace when working with young learners were used with the grade one students. An example of using this technique in a relatable way for the researcher's classroom was when the researcher asked students to describe safe play and reviewed answers using a Venn diagram poster. Rather than exploring broad topics that did not directly translate to the grade one students' daily lives, such as conflict and peace; needs that encouraged all the students to take part in discussions, making it more universally accessible to all the students no matter their interest, age, or gender, were chosen through observation and discussion. During one lesson in September 2014 the whole class examined safety and play. One side of the Venn diagram allowed students to describe what safe play looked like, while the other side allowed them to explore what safe play did not look like. The middle of the diagram followed Sue Liedl's example of "Stop and Think" (Liedl, 2012) [6], addressing moments when conversation should take place in order to reflect on peace or acknowledge conflict. Safety and play are basic needs that people have and are discussed in Marshall Rosenberg's books on Nonviolent Communication (NVC) (Rosenberg and Rosenberg, 2003, pp. 49-69) [1]. A set of cards listing nine different needs were used by the class in order to support students with their communication. On the cards both Eng- 
lish and Chinese words aide the young learners in using language with their discussions. The researcher and teachers deliberately chose the nine needs featured, as they were seen as most prevalent in the classroom. Only nine needs were chosen in order to support the young learners in working with their personal situation and information. This form was designed in order to encourage deep processing as described by Carolin Linse and David Nunan as a way to support young learners with language acquisition (Linse, 2005, pp. 120-134) [8]. Needs such as: safety, communication, play, community, independence, choice, air/food/rest/toilet, choice, and understanding. In October of 2014 it was discovered that some of the cards had gone missing. It was then decided that the cards should be kept on a string in order to facilitate quick use and organization. The cards were used during lesson time and are taken outside of the classroom for use during recess and on field trips. Posters, outlining the steps taken for Compassionate Communication, were found in Conner and Killian's book Connection Across Differences (2011) and follow the NVC communication process (Connor and Killian, 2011, p. 391) [9]. They are divided into four parts, observations, feelings, needs, and requests, and are displayed above the white board in the classroom. English, Chinese, and pictures are used in order to support different learners and their accessibility to language and learning.

\section{Literature Review}

The researcher and teachers used elements found in David A. Kolb's (1984) [7] book on the process of the experiential learning in order to further support their grade one students with steps used for Compassionate Communication and also with accessing language. There origin of the experimental learning process came from three models: The Lewinian Model of Action Research and Laboratory Training, Dewey's Model of Learning, and Piaget's Model of Learning and Cognitive Development (Kolb, 1984, pp. 21-25) [7]. These models support the role and use of the cards for Compassionate Communication in that they support "learning [as] a process whereby knowledge is created through the transformation of experience" (Kolb, 1984, p. 38) [7]. The cards allowed for mobility and flexibility in that they could be taken anywhere and used when different experiences and conflicts might occur. The cards and posters concerning Compassionate Communication steps are used in order to encourage language and support the process of speaking and listening with compassion rather than as an outcome which can be seen as judgement mental and could encourage conflict. Through this Compassionate Communication process, knowledge, skills, and attitudes are being effected. It is hoped that when the Compassionate Communication process and language are used effectively, concrete experience abilities (involving yourself in an experience without bias), reflective observation abilities (reflecting on an observation from many angles), abstract conceptualization abilities (being able to construct new ideas based on observations) and active experimentation abilities (being able to act upon new ideas constructed) can be encouraged and therefore strengthen learning and understanding (Kolb, 1984, p. 30) [7]. Concrete experience abilities (CE) were used when students shared their observations in the first step of Compassionate Communication. Reflective observation abilities (RO) were used in the second and third steps of Compassionate Communication when students were asked to reflect and share their individual feelings and needs. Abstract conceptualization abilities (AC) were used when students were encouraged to listen and reflect upon what others had said. Active experimentation abilities (AE) were used when students created requests based on the discussion and listening steps that took place prior to requests being made.

The researcher and teachers supported the grade one students in following the steps and using the cards in order to support discussion rather than physical reactions to conflicts. Since this study is examining grade one boarding students, a teacher's role is vital in outlining the ideas and process of compassionate communication. There is evidence that shows the more a mentor discusses challenges that might arise in a child's life, the better that child is at developing skills to support them in managing their challenges. In their book on social development in childhood, Smith and Hart (2011) [10] state:

[Those who] discussed and elaborated on psychological aspects in their conversations with their children had children who were advanced in false belief understanding... [and those whom] talk about causes of events and actions [were] linked to children's social cognitive development.

(Smith and Hart, 2011, p. 540)

Those supporting young learners with language and understanding surrounding false beliefs, or having ideas that are different from others, encourage learners to be more open-minded and experience empathy towards oth- 
ers as well as themselves. This is what the researcher and teachers hoped to accomplish when guiding the students with Compassionate Communication cards and steps.

\section{Research Questions}

The initial research question proposed was to identify the effectiveness and use of Compassionate Communication Techniques in an ESL and Chinese Grade One boarding school classroom. Throughout the research and with respect to the use of Compassionate Communication discussed in the previous section, the learning objectives surrounding the initial research question were as follows:

1) To document and classify which students use Compassionate Communication cards when a conflict occurs (guided by teachers or done independently).

2) To identify when these cards are used more often and when they are used less often.

3) To observe and document who will implement the use of cards and guide the students to use them more often or less often.

4) To formulate ideas on how to better improve the effectiveness and use of the Compassionate Communication Techniques used in the classroom.

Based on the initial research question and the learning objectives outlined it is hypothesised that Compassionate Communication techniques will improve from outcomes researched.

\section{Methodology}

There were several research methods used when collecting data for this Grade One class of 25 students, aged 6 7 , at an international boarding school in Shanghai, China. Action research was used to support the overall aim of this study as it supports real life data collection and analysis (Denscombe, 2010, pp. 125-135) [4]. The individual methods used to advance this research included: Interviewing teachers and students, systematic and participant observations done both in and outside the classroom, and documents created by the students (Denscombe, 2010) [4].

\section{Interviews}

Written interviews were emailed to the Chinese homeroom teacher and Chinese teaching assistant, as the researcher is also the English teacher, inquiring about the effectiveness of the techniques used to support Compassionate Communication. The benefit of using written interviews were that they allowed for "straightforward and factual information" and also allowed for flexibility with regards to when the interviews could take place (Denscombe, 2010, p. 173) [4]. Written interviews were used as opposed to questionnaires in order to support qualitative data collection for this small-scale project. A written interview conducted on 8 March 2015 found that different that each teacher had a different opinion on the effectiveness of the techniques used for Compassionate Communication when asked, "What are some challenges with using the needs cards?” (Needs Questions, 2015) [11]. The Chinese homeroom teacher felt that more time was needed for guiding the students in using the cards effectively, while the Chinese assistant teacher and English teacher felt the students needed more support in understanding the meaning associated with needs (ibid, 2015) [12]. The researcher addressed the need for supporting understanding of meaning in relation to the cards 27 March 2015. An email was sent to both the Chinese homeroom teacher and the Chinese assistant teacher outlining steps to be taken in order to encourage Compassionate Communication (Arnesen-Trunzo, 2015) [13]. The email included links from a Nonviolent Communication website, that had translation of steps, feelings, and needs in both English and Chinese for easier language accessibility and understanding (ibid, 2015) [12]. The researcher felt that if the understanding of meaning was made apparent to the teachers, than the teachers would be able to further support their students with their understanding.

In a written interview 22 April 2015 the Chinese homeroom teacher wrote that timing was still a challenge when guiding students to use the cards. The English teacher and Chinese assistant teacher wrote that they were still looking to further the students understanding of the cards (Needs Questions Part 2, 2015) [14]. It was also noted that the Chinese assistant teacher did not follow the links given for the Nonviolent Communication website, while the other two teachers did follow the links (ibid, 2015) [12]. It should be noted that prior to the research taking the Chinese assistant teacher acknowledged having limited comprehension of the English language 
although this role was intended to support both the students and English teacher with communication (Arnesen-Trunzo, 2014) [15]. Over the course of the study meetings between the English teacher and Chinese assistant teacher were held in order to support understanding and use of Compassionate Communication. As the previous section indicates, descriptions on Nonviolent Communication, which Compassionate Communication is based, were shared during these meetings. It is also important to note that in the fall of 2014 the researcher contacted a number of people within the Nonviolent Communication Community in hopes of finding a Chinese speaker NVC trainer that who would be willing to conduct workshops at the school being studied. However, the trainers whom were introduced to the researcher had scheduling conflicts, limited knowledge of the Chinese language or were located in Beijing and unable to attend a school in Shanghai (ibid, 2014) [16].

Interviews of students were conducted on 27 March 2015 (Children’s Questions, 2015) [17]. The Chinese assistant supported with the translation. From these interviews it was discovered that of the 25 students in the study, nine male students reported to have used the cards often, while the other students reported that they did not use the cards (ibid, 2015) [12]. When asked if the students understood the cards twenty three students responded with “yes," one male responded with "a little," and one female responded with "no” (ibid, 2015) [12]. The students were also asked if they felt the cards were helpful. Twenty-three students described the cards as being helpful, while two males, both boarders, described the cards as being "very helpful” (ibid, 2015) [12]. The students were asked how they might make the cards more effective. It is important to note that the researcher was not able to discover if the essence of what was initially written in English was captured in the questions delivered by the Chinese assistant teacher. The responses from the students indicated that there might have been some meaning lost in translation either through the question itself or when describing the responses. The responses showed that eleven students did not know how to make the cards better, while thirteen gave answers suggesting more communication, and one student suggested making the cards available at home (ibid, 2015) [12]. Due to the nature of the Chinese assistant's limited language ability an attempt to respond to the one students request to make the cards available at home was not met.

\section{Observations}

Initially it was thought that both systematicand participant observations would be used in order to document when and if needs cards were utilized during lessons and between lessons. However, creating a systematic observation sheet as described by Denscombe (2010) [4] proved ineffective in this context. Compassionate Communication took place both outside and inside the classroom making quick access to a systematic observation sheet challenging.

Participant observations did take place. Care was taken by the researcher to blend in with the surroundings during participant observations to limit the alteration of data (Wellington, 2000, pp. 93-94) [5]. The researcher, also the English teacher, was present in the classroom and throughout the day. Observational notes were collected from 2 March 2015 until 30 April 2015. The cards were observed being used 57 times during this period. From these observations it was discovered that the majority of students using the cards were male. Males used the cards 48 times, while females used the cards 9 times. Observations showed that teachers often encouraged the use of cards. However, on 18 March 2014, after school, during student's self-learning time, a male student noticed two female students in conflict. Without being told by others the male student brought the cards over to the two female students in order to support them with their conflict. Observations indicated that the cards tended to be used more during recess and in between lessons. This could indicate that conflicts occurred more often in less structured learning environments. This could also show that there was also more time for teachers to support students in following the steps for Compassionate Communication during these times; as the Chinese homeroom teacher indicated before that supporting students with the cards during lesson times was challenging. When cards were used during lesson times students were observed being told by teachers to look at their needs cards in different areas of the room, while the teachers continued teaching their lessons. Once there was a break in teaching, or if the Chinese assistant teacher had time, the teacher or Chinese assistant teacher would then spend time discussing the conflict with the students privately. Since the researcher had limited knowledge of Chinese, it is not known if the steps for Compassionate Communication were used during Chinese lessons. Steps for Compassionate Communication were used during English lesson in order to model how to use the cards and practice the language associated with the steps following Compassionate Communication. Data collected through observational notes and cross referenced with students' personal information indicated that those stu- 
dents born in 2008 (7 years of age) tended to use the cards more often than those students born in 2007 (8 years of age). There was no indication that boarding students used the cards more or less than non-boarding students. Those students born in colder months, October-February, used the cards more often than those born in warmer months, with one male born in July.

\section{Documents}

In order to document the use of cards when the researcher was not present it was initially thought that the students could create documented evidence of card use. At the beginning of the study, small pieces of paper were created for students to sign when the cards were used. Both students were asked to sign the piece of paper along with the date and the name of the person they had a conflict with. Next to the name the students were asked to place a tick, indicating that they felt the other person had listened, or a cross, indicating that they felt the other person had not listened. The documents were collected daily and placed in a box/jar by the students, supporting confidentiality by folding the paper in half in order to support anonymity, as mentioned in British Educational Research Association (BERA)'s Ethical Guidelines (Ethical Guidelines for Educational Research, 2011, pp. 8-9) [18]. This data collection process was found to be ineffective, due to time restraints, space and writing skills of the students. The paper initially used March 2015 was small and proved challenging for students to write their names on. When larger pieces of paper were introduced there was limited space for the paper and it was often moved to the recycled paper box in the classroom. The researcher also questioned the validity of these documents, as it was difficult to assess the credibility of student tick and cross assessment of listening (Denscombe, 2010, p. 222) [4].

On 10 March a grid was created by the researcher in order satisfy the documentation of card use and to limit the amount of writing students would need to produce. The grid was placed behind the sink in the classroom, as there was limited wall space. During a lesson observation 18 March it was recommended that the grid be taken down, as it was not being used effectively (Mcquillan, 2015) [19]. After this documents were no longer used to support research related to Compassionate Communication Techniques.

\section{Analysis of Findings}

The data collection from interviews showed conflicting outcomes. Teacher written interviews suggest that conveying the meaning of needs in Compassionate Communication and encouraging steps to be followed when producing language proved challenging, due to time constraints and language limitations. Student interviews indicate a strong understanding of the cards, with $100 \%$ of the population indicating that they understood. This may be related to Kolb's (1984) [7] Experimental Learning Theory, in that the steps for Compassionate Communication were accessible throughout the day for students. Kolb (1984) [7] states:

Learning in a sense is an active, self-directed process that can be applied not only in the group setting but also in everyday life... Knowledge is the result of the transaction between social knowledge and personal knowledge.

(Kolb, 1984, p. 36)

By providing students with an opportunity to experience Compassionate Communication in environments that had varying degrees of structure, students may have been supported with the understanding of the cards meanings as well as the steps associated with them. Allowing students to experience the cards in different environments could also support Stephen Krashen's Affective Filter Hypothesis, in that anxiety might be lowered supporting comprehension and language acquisition (De Bot, Lowie and Verspoor, 2005, pp. 36-37) [20].

Conflicting interviews from both the English teacher and Chinese assistant teacher indicated a lack of understanding. This could be related to the validity of the questions being asked as the interviews were written interviews. The questions and answers given did not specify which area of understanding was lacking in the Compassionate Communication process (Needs Cards, 2015) [21].

Student sample size was small and limited to 25 students. However, student interviews indicated limited use of the cards with $36 \%$ of the population using the cards often and $64 \%$ indicating limited use. This could be linked to negative connections placed on the cards, as the cards were used during conflicts rather than celebrations.

Observations indicated the use of cards were more prevalent outside of the classroom, rather than inside. This 
could be due to time, which the Chinese homeroom teacher mentioned in a written interview she wanted more of. Observations also showed males using the cards more than females. Since the cards were only used during times of conflict this could indicate a difference in cognitive development between the two genders, though more research would need to be done in this area. Observations also indicated card use allowed students and teachers time to continue work on individual tasks, either teaching or choosing cards associated with their needs. Although the Chinese homeroom teacher indicated a desire for more time to support students in the process of Compassionate Communication, the cards seemed to promote a time for reflection for students in conflict and time for teachers to continue with their lesson. If time allowed a critical review of card use might be implemented in the form of a longitudinal study, whereby the students could tracked over a longer period of time while using the cards (Bell, 2010, pp. 109-112) [22].

\section{Conclusion}

The caveats for this study, including language barriers and limited understanding of the steps for Compassionate Communication, suggest several avenues for replication and additional research. With regard to linguistic differences and time restraints the present study was found to offer few improvements of techniques. However, the card system seemed to support students in different educational learning environments and guided students in language production. Observations and interviews indicated that the cards were useful to some extent, as they provided students with time to reflect and could be used in different locations. However, this study was found to be inconclusive due to limitations including sample size, research method validity, and time scale. If these limitations are addressed with future research it could allow for more improvements of Compassionate Communication Techniques in classrooms.

\section{References}

[1] Rosenberg, M. and Rosenberg, M. (2003) Non-Violent Communication. Puddle Dancer, Encinitas.

[2] (2014) Teachers Regulations.

[3] Beard, C., Wilson, J. and Beard, C. (2006) Experiential Learning. Kogan Page, London.

[4] Denscombe, M. (2010) The Good Research Guide. McGraw-Hill/Open University Press, Maidenhead.

[5] Wellington, J. (2000) Educational Research. Continuum, London.

[6] Liedl, S. (2012) NVC Training.

[7] Kolb, D. (1984) Experiential Learning. Prentice-Hall, Englewood Cliffs.

[8] Linse, C.T. and Nunan, D. (2005) Practical English Language Teaching: Young Learners. McGraw-Hill ESL/ELT, New York.

[9] Connor, J. and Killian, D. (2011) Connecting across Differences. Puddle Dancer Press, Encinitas.

[10] Smith, P. and Hart, C. (2011) The Wiley-Blackwell Handbook of Childhood Social Development. Wiley-Blackwell, Chichester.

[11] Needs Questions (2015) [Interviews].

[12] (Ibid, 2015).

[13] Arnesen-Trunzo, M. (2015) Supporting Me with Our NVC Class Project [Email].

[14] Needs Questions Part 2 (2015) [Interviews].

[15] Arnesen-Trunzo, M. (2014) Chinese Speaking NVC Trainers? [Email]. Arnesen-Trunzo, M. (2014) Notes.

[16] (Ibid, 2014).

[17] Children's Questions (2015) [Interviews].

[18] (2011) Ethical Guidelines for Educational Research. 2nd Edition [ebook], BERA, London. https://www.bera.ac.uk/wp-content/uploads/2014/02/BERA-Ethical-Guidelines-2011.pdf

[19] Mcquillan, P. (2015) Meetings etc. [Email].

[20] De Bot, K., Lowie, W. and Verspoor, M. (2005) Second Language Acquisition. Routledge, London. http://dx.doi.org/10.4324/9780203446416

[21] (Needs Cards, 2015)

[22] Bell, J. (2010) Doing Your Research Project. McGraw-Hill Open University Press, Maidenhead. 